\title{
COMPUTATIONAL FLUID DYNAMICS APPLICATION FOR THE EVALUATION OF A COMMUNITY ATRIUM OPEN SPACE DESIGN INTEGRATED WITH MICROCLIMATE ENVIRONMENT
}

\author{
WU, K.-L. ${ }^{1}-\mathrm{HSIEH}$, C.-M. ${ }^{2 *}$ \\ ${ }^{I}$ Department of Urban Planning and Landscape Architecture, National Quemoy University, \\ Taiwan, ROC, No. 1 University Road, Jinning, Kinmen, 892, Taiwan \\ (e-mail: klwu3890302@gmail.com; phone: +886-926-830-728) \\ ${ }^{2}$ Department of Urban Planning, BIG Data and Urban Analytics LAB, Tongji University, \\ 1239 Siping Rd., Shanghai, China \\ *Corresponding author \\ e-mail: chunming@tongji.edu.cn; phone:+86-21-6598-2345; fax: +86-21-6598-1002
}

(Received $16^{\text {th }}$ Jun 2017; accepted $3^{\text {rd }}$ Oct 2017)

\begin{abstract}
This study aims to develop an approach which integrates the concept of climate-sensitive design with housing community design for the design of better residential buildings fitting into local wind environment. Employing research methods involving field investigation and computational fluid dynamics (CFD) simulation, the ventilation environment of four typical community atrium spaces were examined and compared in this study. Through a combination of CFD simulation and scenario-based design studies, the research results reveal that the typical long-shape building blocks with high-density housing development lead to poor natural ventilation in atrium open spaces. The research also indicates that if the openings of building masses and atrium can match the prevailing wind direction, the ventilation in community atrium open spaces will be significantly improved, but the overall effects are also affected by several design factors such as the distance between buildings, the size and shape of urban blocks, organization of building masses, and whether or not the wind corridor effect is effectively utilized. It is suggested for further research that more detailed issued-based CFD simulations (e.g., various land use controls or user preferences) of the relationship between wind environment and various design strategies should be conducted in the early stage of the entire design process to obtain the improvement in ventilation environments.
\end{abstract}

Keywords: computation fluid dynamic (CFD); housing design; ventilation; wind environment; thermal environment

\section{Introduction}

Given the impacts of global climate change and the urban heat island effect, sustainable design methods by which to create a community environment that better fits into the local microclimate characteristics has become an important research issue in both urban design and community design (Mirzaei and Haghighat, 2010; Jan et al., 2013; Hsieh et al., 2016; Yang et al., 2017). Climate change and the negative effects of urbanization on the living environment, such as high temperatures, increases in PM 2.5, and increases in the heat island effect, make the aerodynamic properties of urban areas increasingly important in architectural and urban design, especially in hot and high density urban areas (Chao and $\mathrm{Ng}, 2014$; Yim et al., 2014). Wind passing from rural areas into a city provides cleaner and cooler air into urban canopy layers in summers and good ventilation has been noted as one of the possible mitigation solutions to improve urban air environments and mitigate the impact of heat island effect (Hang, 2013; Hsieh and $\mathrm{Wu}, 2012$ ). Good ventilation not only helps eliminate pollutants, it also 
improves outdoor human comfort by accelerating heat exchange, as well as enhances the natural ventilation capacity of interior spaces (Givoni, 1998; Ishida et al., 2005; Xie et al., 2006).

Urban wind corridors can result from roads, open spaces, and passages through which air reaches the interiors of urbanized areas (Suder and Szymanowski, 2014). Over the years, urban wind research has investigated turbulent flow conditions in different street canyon models (Shi et al., 2015; Allegrini et al., 2015). Building blocks with limited open spaces between them, uniform building heights, and large podium structures have led to lower permeability for urban air ventilation at the pedestrian level ( $\mathrm{Ng}, 2009$; Yuan and $\mathrm{Ng}$, 2012). High density housing development patterns and improper building layout in many dense urban areas have affected the ventilation of residential buildings as well as the comfort of residents (Walton et al., 2007; Du et al., 2017). These kinds of studies have shown that there are significant impacts of site planning and building layouts on the resulting wind environment around buildings. Therefore, it has become a great challenge for both urban designers and architects to determine how to better utilize the wind environment and natural ventilation to improve the outdoor wind environment as well as to enhance air quality in urban areas (Hsieh and Huang, 2016; Peng et al., 2017).

Previous studies have also revealed the importance of carrying out an environmental assessment of the available alternatives in the design stage of urban and building projects (Asfour, 2010). However, in spite of the fact that some research effort has been made, the lack of good interaction between urban wind environment researchers and urban space designers, together with a shortage of easy-to-use and easy-to-understand simulation tools for evaluating design alternatives in the design process has limited the practical application of related research. In terms of methodology and analytical tools, the effects of the urban building arrangement on the wind environment have been investigated through wind tunnel experiments or numerical simulations, such as Computational Fluid Dynamics (CFD). CFD has become a commonly used numerical simulation method and analytical tool for studying the wind environment (Takahashi et al., 2004; Mochida and Lun, 2008; Hu and Ryuichiro, 2013). It has some important advantages over wind tunnel testing. For example, wind tunnel measurements are generally performed at a few selected points under similar requirements in urban models. CFD, on the other hand, is conducted at full scale and provides whole-flow field data and information on the relevant parameters at all points of the computational domain (Blocken et al., 2012; Mirzaei and Caemeliet, 2013) Moreover, CFD is being increasingly used to assess pedestrian-level wind conditions in urban areas (Wu et al., 2013). Because of these advantages, CFD is being increasingly used to study a wide range of wind-related environmental problems in urban areas, such as urban air pollution and natural ventilation of community building design (Gromke et al., 2015; Mora-Pérez et al., 2015; Wang and Li, 2016).

It is also worth mentioning that, thanks to the development of numerical simulations, a more efficient design approach and design project evaluation has been made possible. Generally speaking, the entire design process normally includes three stages: a predesign stage, a design stage, and various post-design stages. In an age when digital simulation tools have not been widely applied in design practice, many conceptual design ideas have been difficult to put into practice because they could not be validated before being mass produced. Also, in a design age that is heavily reliant on drawing tools such as pens and papers, it is quite often the case that many design products have 
been manufactured without pre-design evaluations. Although sometimes post-design evaluations or post occupancy evaluations (POEs) have been conducted to help identify some design mistakes, it is often too late to make any adjustment because the products or buildings have already been manufactured.

Similar cases in community housing design, systematic considerations of the topic are limited and normally not included in decision-making at the pre-design and design stage in community planning and design. In spite of these effects being noticed by researchers, relatively few efforts have been made by urban designers and architects to integrate the effects of natural ventilation into block-level community housing design. In high density Asian cities for example, in order to allocate the maximum number of housing units or maximum Floor Area Ratio (FAR), natural ventilation is normally not seen as a key consideration in organizing housing layout and building masses. Moreover, local building codes in many Asian cities also have failed to take the effect of the wind corridor into consideration in arranging building setback and design guidelines for community open spaces.

Unlike the past approach, current applications of digital simulation tools such as CFD, enable design problems to be identified in the pre-design stage or sketch design stage. Moreover, with the help of computer simulations, an integrated product evaluation process that links the design stages, simulations, and assessments can be established before products are actually manufactured. For example, the development of CFD has resulted in the widespread use of this technique not only as an environmental research tool but also as an architectural design tool. In view of this dilemma, this research is an attempt to address the issues indicated above by using four prototype building layouts in Tainan City, Taiwan as case settings. The practical applications of wind engineering (CFD modeling) on architectural design and community open space design are discussed to together with considerations of housing market requirement. This study is aimed toward changing traditional experience-based design methods toward more scientific wind environmentally-sensitive architectural design an community design, in order to ensure that the surrounding wind environment of the proposed residential buildings is adequately considered. Employing research methods involving field investigation and CFD simulation, this study is an attempt to explore two research issues: (1) how to systematically analyze the influence of community building layouts and atrium designs on the ventilation of community outdoor spaces and (2) how to suggest suitable building layouts and open space design principles that strengthen the coordination between the local wind environment and the design of community open spaces. Based on our empirical approach, the effect of building arrangements on average ventilation efficiency is numerically evaluated in selected residential areas at the pedestrian level, and practical design suggestions are proposed to serve as a guide for better urban ventilation design.

\section{Materials and methods}

\section{Study area}

Tainan City $\left(23^{\circ} 0^{\prime} 16^{\prime \prime} \mathrm{N}, 120^{\circ} 13^{\prime} 10^{\prime}\right.$ 'E) is located in a tropical climate zone, considerably close to the Tropic of Cancer which divides the subtropical zone and tropical zone. Known as the fourth most populated city in Taiwan, Tainan City is also highly urbanized. The heat island intensity, defined as the maximum air temperature 
difference between the urban and rural areas of Tainan City during the nighttime and daytime, is $3.4{ }^{\circ} \mathrm{C}$ and $3.2{ }^{\circ} \mathrm{C}$, respectively (Lin et al., 2005; Lu, 2008).

According to data from years 2001-2016, the average temperature from June to September was more than $28.5{ }^{\circ} \mathrm{C}$. Among them, the temperature in July was the highest, recorded as $29.6{ }^{\circ} \mathrm{C}$ during the summer season (Hsieh et al., 2016). Furthermore, Tainan City is close to the sea and therefore having high humidity in summer. The wind environmentally-sensitive architectural design which consider how the natural ventilation can be utilized becomes an crucial step to improve the outdoor wind environment. The above weather characteristics, make Tainan City a good candidate for wind environment analysis, one of the main objectives of this study. It is a common issue in the southern part of China and also the Southeast Asia areas, especially for those places with the similar weather characteristics of high air temperature and humid in summer (Feriadi and Wong, 2004; Nguyen and Reiter, 2014; Priyadarsini et al., 2014; Sharmin et al., 2017).

\section{Field measurement design}

To achieve the purposes of this research, a representative residential neighborhood next to Barclay Park in Tainan City, Taiwan (a subtropical climate zone) was selected as the empirical case setting. The residential neighborhood includes four types of housing communities with different building masses and building layouts. Each of them is a complete block development, and the buildings are typical housing types in Taiwan. Given that there are four prototypes of residential building layouts appearing in the same microclimate environment, this residential neighborhood provides an excellent case for addressing the relationship between the outdoor wind environment and building layouts as well as the effects of atrium design. The location and current situation of study area is shown in Fig. 1.

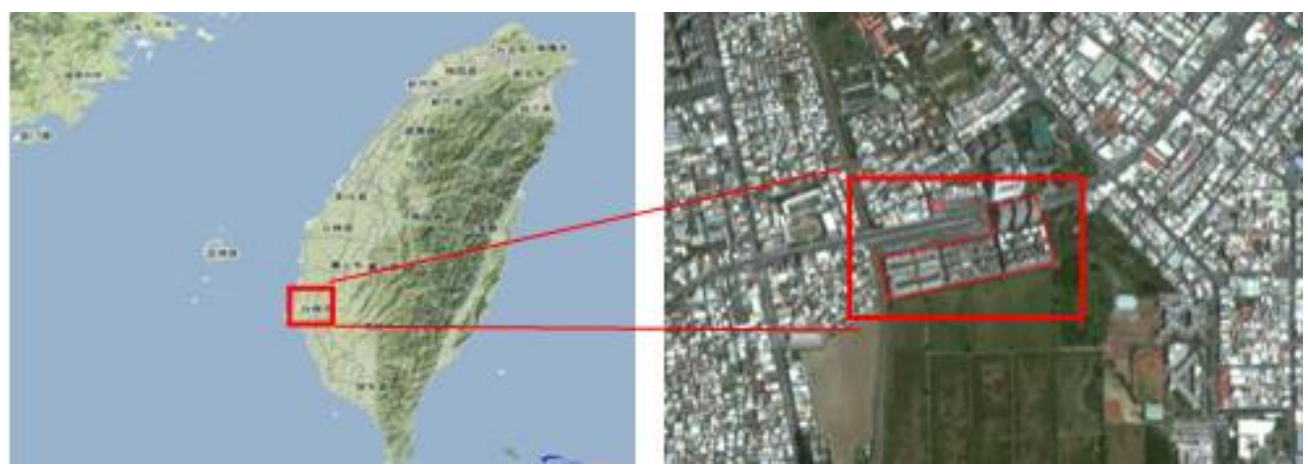

Figure 1. Location map of study area

The famous Barclay Ecological Park is located on the east side of the study area, and a large agricultural experimental farm was located on the south, which has been just rezoned by the Tainan City Planning Commission as a new urban development site, but new land development has not occurred yet. To the north is a 40-M main road, and to the west are a large parking lot and some low-rise houses. Given that the prevailing wind direction in summer of the study region is mostly southerly, it can be assumed that the impact of the surrounding buildings on the local wind environment is small. 
The selected residential neighborhood (the study area) contains four different types of atrium housing communities (Figs. 2 and 3). Type A Community contains one $63 \mathrm{~m}$ high-rise elevator building complex (three sets of connected 20-story apartment buildings), which has a small-scale unilateral open atrium facing the south. Type B Community contains two blocks; each has several connected 7-story apartment buildings, with a height of $24 \mathrm{~m}$ and a narrowed atrium with two unilateral openings. Type C Community is a townhouse residential community shaped by 4 unit building complexes with a building height of $16 \mathrm{~m}$. It contains two residential blocks; each has a ribbon-shaped atrium open space with three openings. Type D Community is a row house residential community shaped by connected 5 -story buildings $(16 \mathrm{~m})$, with the opposite side opening into a ribbon-shaped atrium in each block. All the blocks are densely developed in order to obtain the maximum number of housing units, and this is a common situation in land development practice in Taiwan in order to increase economic profit.

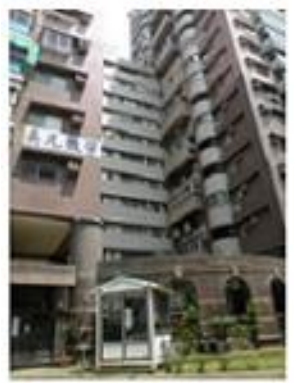

(a)

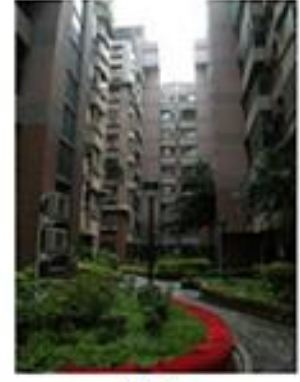

(b)

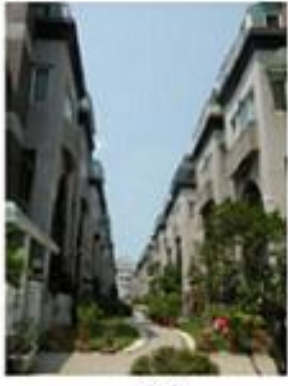

(c)

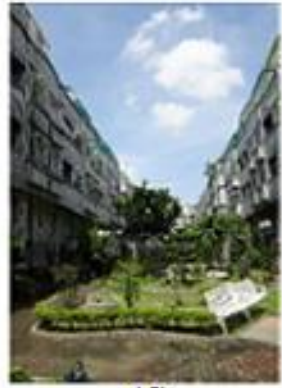

(d)

Figure 2. Open spaces of residential community atrium in study area.(a) Community: elevator apartment with opening on one side. (b) Community: 7 stories apartment with two openings on one sides. (c) Community: belt atrium community with opening on two sides. (d) Community: belt atrium community with opening on the edge

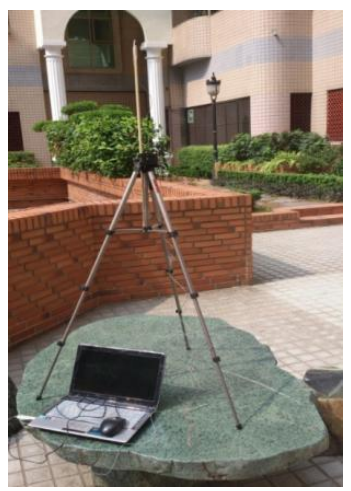

Figure 3. Measurement equipment

The measurement time of our survey was between July 5th and July 28th of 2014. This three weeks period in Taiwan is when the weather is the hottest, and the impact of the urban heat island is the strongest. Therefore, a study on how to enhance the ventilation of atriums in such communities is critical in order to create a comfortable environment for outdoor activities. The microclimate measurement was conducted on 
selected spots, at selected time periods in the mornings and afternoons during the three weeks (9:00-11:00 in the morning and 2:30-4:30 in the afternoon) when the weather conditions were typically torrid without obvious strong wind. The major factors examined in the survey were wind speed, temperature, humidity, and the perceived comfort of users of each atrium space. The measurement equipment included Cambridge Accusense UAS 1500 anemometers (Fig. 3), AM-4214SD anemographs, and HT3007SD hydro-thermal meters. The Cambridge Accusense UAS 1500 anemometer, whose accuracy can reach $0.10 \sim 20 \mathrm{~m} / \mathrm{s} \pm 5 \%$, was assembled on a tripod $1.5 \mathrm{~m}$ above the ground (the range of wind often affects pedestrian comfort). With regard to the arrangement of the measurement points (Fig. 4), the points were carefully selected to reflect the critical points that influencing atrium wind fields and user comfort, including points in the main nodes of outside activity spots and wind paths, and in the opening of the atriums. Effort was also made to keep the survey points equally and spatially distributed. Because the Type A Community is the highest building in the study area, a measurement point was set on the floor of the attic to measure the surrounding wind speed, which was imported into the CFD analysis later as a baseline parameter.

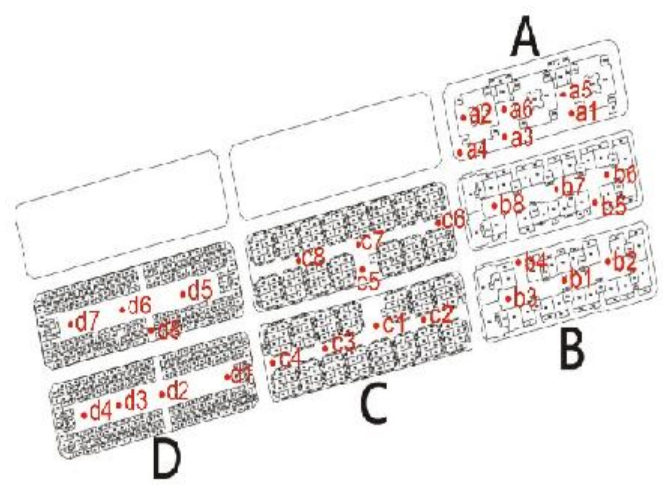

Figure 4. Map of measurement points

\section{CFD simulation}

Computation fluid dynamics (CFD) numerical simulations were employed to analyze the surrounding wind environment of the buildings. In regard to the setting of boundary conditions for the CFD simulation, the velocity inlet was set to be the gradient wind, where the vertical wind speed distribution was represented by the power law profile (Eq. 1). The land surface was set to be a no-slip condition.

$$
\frac{U_{(z)}}{U_{0}}=\left(\frac{z}{\delta}\right)^{\alpha}
$$

where

$U_{0}$ : wind speed $(\mathrm{m} / \mathrm{s})$ outside of boundary layer (also known as the gradient velocity)

$U_{(Z)}$ : the wind speed at the height of $Z(\mathrm{~m} / \mathrm{s})$

$Z$ : the reference height $(\mathrm{m})$ (set to be the height of Building $A=60 \mathrm{~m}$ in this case)

$\delta$ : the height of gradient $(\mathrm{m})$

$\alpha$ : power law value (index) 
In accordance with relevant research practices, the height and the power law value of the boundary layer was determined depending on ground conditions. The simulation area was dominated by middle-story buildings, so the power law value was set at 0.25 , and the gradient height was set at $400 \mathrm{~m}$. The remaining parameter settings are shown in Table 1 .

Table 1. Parameters of boundary condition settings

\begin{tabular}{c|c}
\hline Items & Setting \\
\hline Wind direction & $\mathrm{S}$ \\
Wind velocity $(\mathrm{m} / \mathrm{s})$ & 3.40 \\
CFD scheme & Central difference scheme \\
Governing equations & Navier-Stokes equations \\
Boundary volume $(X \times Y \times Z)$ & $1500 \mathrm{~m}(\mathrm{~N}-\mathrm{S}) \times 1500 \mathrm{~m}(\mathrm{E}-\mathrm{W}) \times 450 \mathrm{~m}$ \\
Total mesh number & $7,957,000$ meshes \\
Reference height $(\delta)$ & $60 \mathrm{~m}$ \\
Power law value $(\alpha)$ & 0.25 \\
\hline
\end{tabular}

In the case under study, the simulation area is surrounded mainly by a park, a large area of agricultural land and a large parking lot. Because there are no buildings of significant mass in the major wind directions of the study area, the influence of surrounding buildings on the wind environment was considered to be negligible in the model calibration. When calculating the flow field using a CFD model simulation, the setting up of a reasonable grid system and selection of suitable boundary conditions are key requirements for efficient computer calculation. Based on the experiences discussed in previous relevant studies, the boundary condition for the simulation was set to be 10 times of the height of the main buildings, and the height of the calculation area was set to be 5 times of the height of the main buildings. A structural grid was used in order to enhance the simulation accuracy. Due to the fact that the fluid variation around the buildings is much larger than that around other areas, a more refined grid system was developed around the buildings in order to get more accurate simulation results. WindPerfectDX was the software employed in this research. Its advantages include the capacity to develop a very fine grid system for a simulation as well as the ability to import the Sketch up 3D files easily and directly. Also, it has a strong visualization capacity for simulation results, which makes communication with developers and architects much easier.

\section{Results}

In order to validate whether the simulation results could be used for reference to community planning and design, a simulation model based on the current situation was first calibrated, and then the CFD simulation results were compared with the results of our microclimate survey conducted on the site. The model validation process involves making sure the CFD simulation model is reasonable and that the results are accurate and could be used for the evaluation of design plan. After the model validation process, 
the proposed alternative plans were then analyzed and compared. The model validation was conducted using the measured wind speed and prevailing wind direction, which is southerly. The wind speed measured at point a2 on the roof of the Type A 20-story building was used as the initial inflow wind speed.

The simulation results were compared with the actual measured results for the measurement points to examine the accuracy of the simulation model. Part of the results are shown in Fig. 5, which is a simulation based on southerly wind at an average speed of $1.3 \mathrm{~m} / \mathrm{s}$. The results indicate that the simulation values at points a6, b1, b5, c1, c8, d5 were all very close to the measured values, indicating that the model was reasonable. The simulation results of measurement points a1 and $\mathrm{d} 2$ were slightly different from the measured values, but the differences were both within an acceptable level (less than $0.09 \mathrm{~m} / \mathrm{s}$ ). In addition, a correlation analysis between the simulation values and measured values was conducted for all 30 measurement points, and the results showed a correlation coefficient $r=0.86$, which indicates that the simulation results were close to the measured results. This further confirmed that the CFD simulation model could be used in the subsequent scheme assessment and analysis.

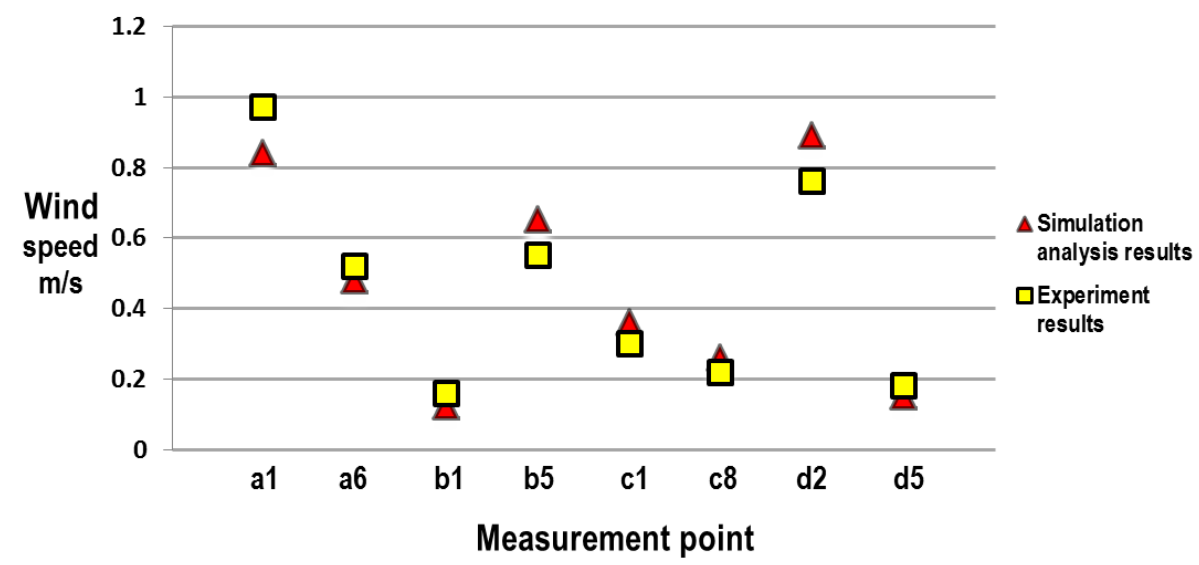

Figure 5. Measurement point comparison between simulation analysis results and experiment results

\section{Evaluation of simulation results for community development plan on different blocks}

After confirming the reliability of the proposed simulation model, a CFD simulation was conducted to evaluate the atrium ventilation performance of the four types of housing communities. The main process of the analysis involves calculating the spatial distribution of wind speed at pedestrian height in the outdoor space of the four communities. The CFD simulation was conducted using the prevailing wind direction in the summer. According to a field survey and the information obtained from a local weather station, southerly wind was used as the prevailing wind direction. The simulation results are shown in Fig. 6. The results reveal that "the position in which buildings face the wind field" and "the form and position of the openings in the community atrium in relation to the wind field" are two key factors influencing the ventilation condition in the community atrium situation. For the assessment of human comfort from viewpoint of landscape architects and urban planners, the high wind speed $(\mathrm{u} \geq 1.0 \mathrm{~m} / \mathrm{s})$ and low wind speed $(\mathrm{u}<1.0 \mathrm{~m} / \mathrm{s})$ areas were defined (Hsieh et al., 2016). Moreover, pedestrian-level natural ventilation in the street canyon was assigned as the 
stagnant $(\mathrm{u}<0.3 \mathrm{~m} / \mathrm{s})$, poor $(0.3 \mathrm{~m} / \mathrm{s} \leq \mathrm{u}<0.6 \mathrm{~m} / \mathrm{s})$, low $(0.6 \mathrm{~m} / \mathrm{s} \leq \mathrm{u}<1.0 \mathrm{~m} / \mathrm{s})$, satisfactory $(1.0 \mathrm{~m} / \mathrm{s} \leq \mathrm{u}<1.3 \mathrm{~m} / \mathrm{s})$, and good $(\mathrm{u} \geq 1.3 \mathrm{~m} / \mathrm{s}$ ) in Hong Kong (Yuan and $\mathrm{Ng}, 2012$ ). According to previous studies and the results of our interviews with community residents, a wind speed of pedestrian field between $1.0 \mathrm{~m} / \mathrm{s}$ and $2.5 \mathrm{~m} / \mathrm{s}$ is a more comfort wind range for community atrium open space design, and the atrium open spaces of the four selected housing communities in urban blocks were examined subsequently.

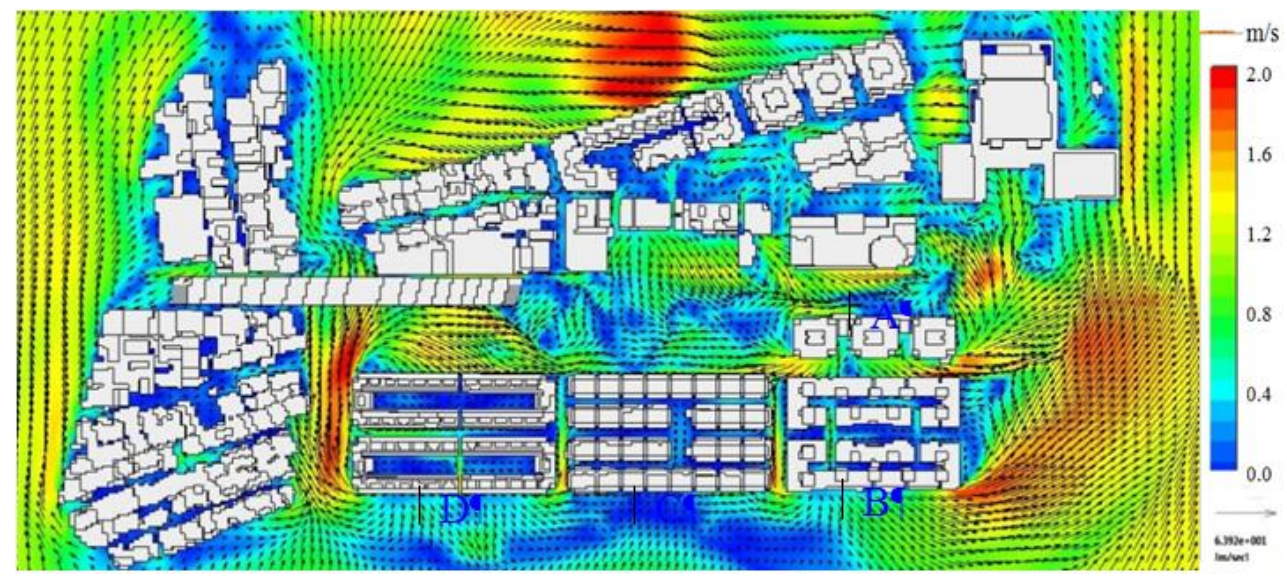

Figure 6. CFD results of residential community environment (regional scale)

The atriums, directly facing the direction of the summer prevailing wind, should have a better ventilation conditions compared to those of housing community type A. However, our analysis results show that the type A residential buildings in the back of building blocks perform better in terms of outdoor atrium ventilation. A possible explanation for this phenomenon is that the building blocks facing the windward side (building blocks on the outside of south facade) in type B and type C housing communities did not provide a corresponding opening on the windward side, so the airflow has to get in from the side entrances and the atrium entrance on the back side of the buildings, which leads to poor atrium ventilation. As for housing community type D, although these have openings on the windward side, the size of the opining is relatively small, and the atrium is too narrow and long, so the wind corridor effect can not expand to the entire atrium, which therefore leads to poor ventilation of the entire outside open space.

The research results also reveal that if there are sufficient openings provided in linear atrium communities (housing community type $\mathrm{C}$ ), or if the position of the atrium opening is helpful for enhancing the airflow convection of the atrium (housing community type B), the outside ventilation condition will be significantly improved in areas that can be affected by air convection. In addition, our empirical results also indicate that "the relationship between the axial building layout and the wind corridor" and "the separation distance between buildings" both have obvious influences on community outdoor ventilation. For example, the arrangement of the long axis in housing community type $\mathrm{C}$ caused failure to match the prevailing wind direction and thus contributed to a weak effect of the wind guiding function. Similarly, housing community type D has only a narrow opening facing the windward side, which also limits the wind guiding effect of the passing wind corridor. 


\section{Discussions}

After exploring the possible reasons leading to poor atrium ventilation in the study cases, two alternative community design plans were proposed, and a CFD simulation was used to evaluate the effects of each plan. By considering consumer demand, housing development and local housing market trends (the demand for maximization of total floor area and the total number of housing units in order to make significant profit) as well as the principles of community ventilation design, two refined alternative plans were provided: one is a minor adjustment plan, and the other is a complete block redesign plan. Together with the plan of "business as usual" (the current one), there were a total of three plans to be simulated and compared. The architectural perspectives and selected elevation views of these plans are shown in Figs. 7 to 9.

The two alternative plans have different planning goals and considerations. The minor adjustment plan (community residential building plan 2, Fig. 8) adds ventilation openings and vents in selected buildings, while trying not to reduce the total floor area and total housing units in order to meet the expectations of developers who are seeking profit.

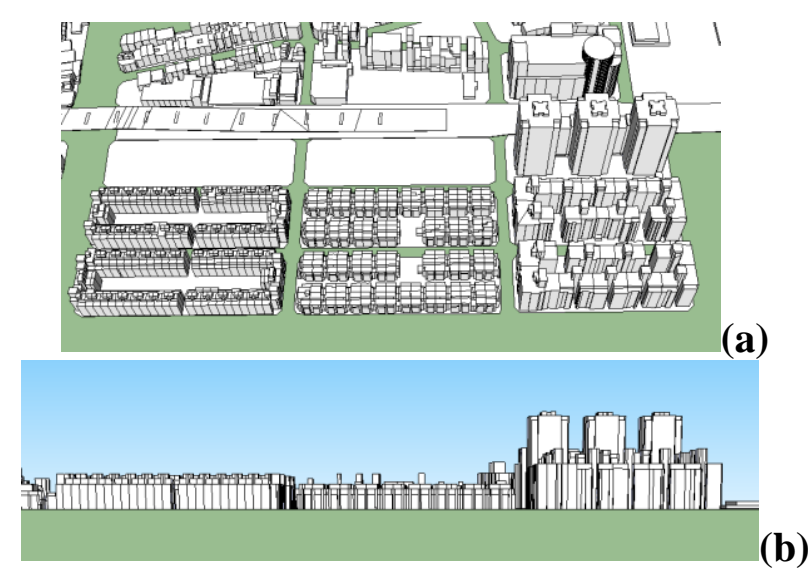

Figure 7. Community residential building plan 1 (current situation). (a) Perspective view. (b) The south elevation view
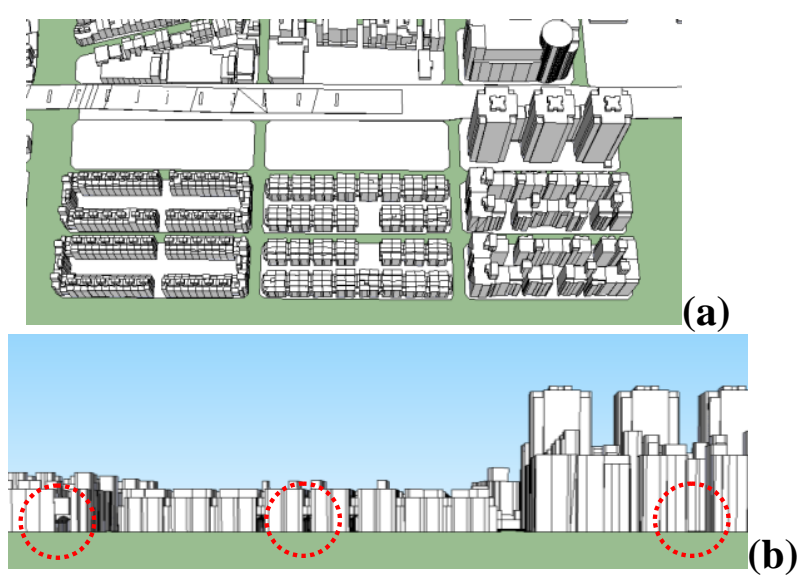

Figure 8. Community residential building plan 2 (slightly-adjusted situation). (a) Perspective view. (b) The south elevation view 


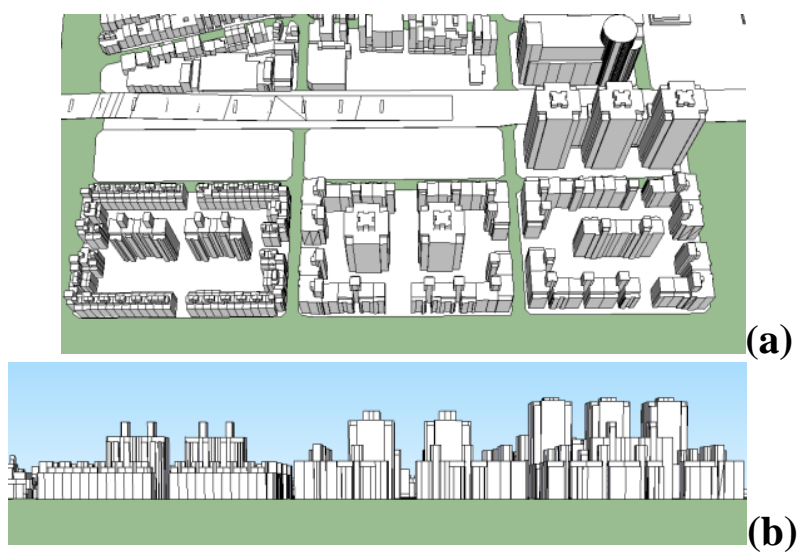

Figure 9. Community residential building plan 3 (climate-sensitive adjustment situation). (a) Perspective view. (b) The south elevation view

The design methods of the plan included adding one opening on the south side of the buildings of Community Type $\mathrm{B}$, and then transferring the decreased floor area resulting from the new opening to the top floor of the buildings on both sides of the community entrance. This creates double effects: it maintains the total floor area on the one hand, while creating an enhanced image of the community entrance. A similar approach was used in Community Type $\mathrm{C}$, where several air vents were added to the three connected building units in the middle building complex facing south, while the decreased floor area was added to the top floor of the buildings near the community entrance to create enhanced visual effects. As for Community Type D on the left, air vents were placed at the junctions of the building units on the four corners, and the decreased floor area was added to the top floor of the buildings next to the community entrance to enhance the entrance image.

The above-mentioned minor adjustments were made on the basis of a planning goal to add ventilation openings and vents to existing building forms and building masses, while trying not to decrease the total floor area and the number of housing units. Based on our interviews with the local land developers, this approach was highly accepted by them. The actual effect of the improvement atrium ventilation in this approach, however, will need to be examined based on the results of the simulation analysis.

As for the second alternative plan (community residential building plan 3, Fig. 9), it involves a large adjustment in which building blocks and building type mix are redesigned based on the concept of climate-sensitive design and the consideration that without significantly reducing the allowed floor area ratio of land development. The original two long narrow shaped blocks in Community Type B, Community Type $\mathrm{C}$ and Community Type D are combined into one block for each community. The size of the new block is about $80 \mathrm{~m} \times 100 \mathrm{~m}$, which is a block size good for human walkability and a better arrangement for building layout. The building types and arrangement of the building masses are also redesigned, and the scale of atriums, the building configuration, and the distances between buildings are all reconsidered so as to try to obtain the optimal atrium ventilation. Moreover, what is worth mentioning is that a combination of town houses and mid-rise apartment buildings are adopted in the building forms of Community Type $\mathrm{C}$ and Community Type $\mathrm{D}$. The combination of different housing types and sizes reflects different housing prices and market demand, 
which is helpful to introduce households with various socio-economic backgrounds, and therefore contributes to the diversity of the population in these communities.

The simulation results for the three plans using CFD software are shown in Fig. 10. Fig. 10 shows an enlarged image of the four communities. These results reveal that the two refined schemes, to various degrees, enhanced the natural ventilation of the atrium open spaces.

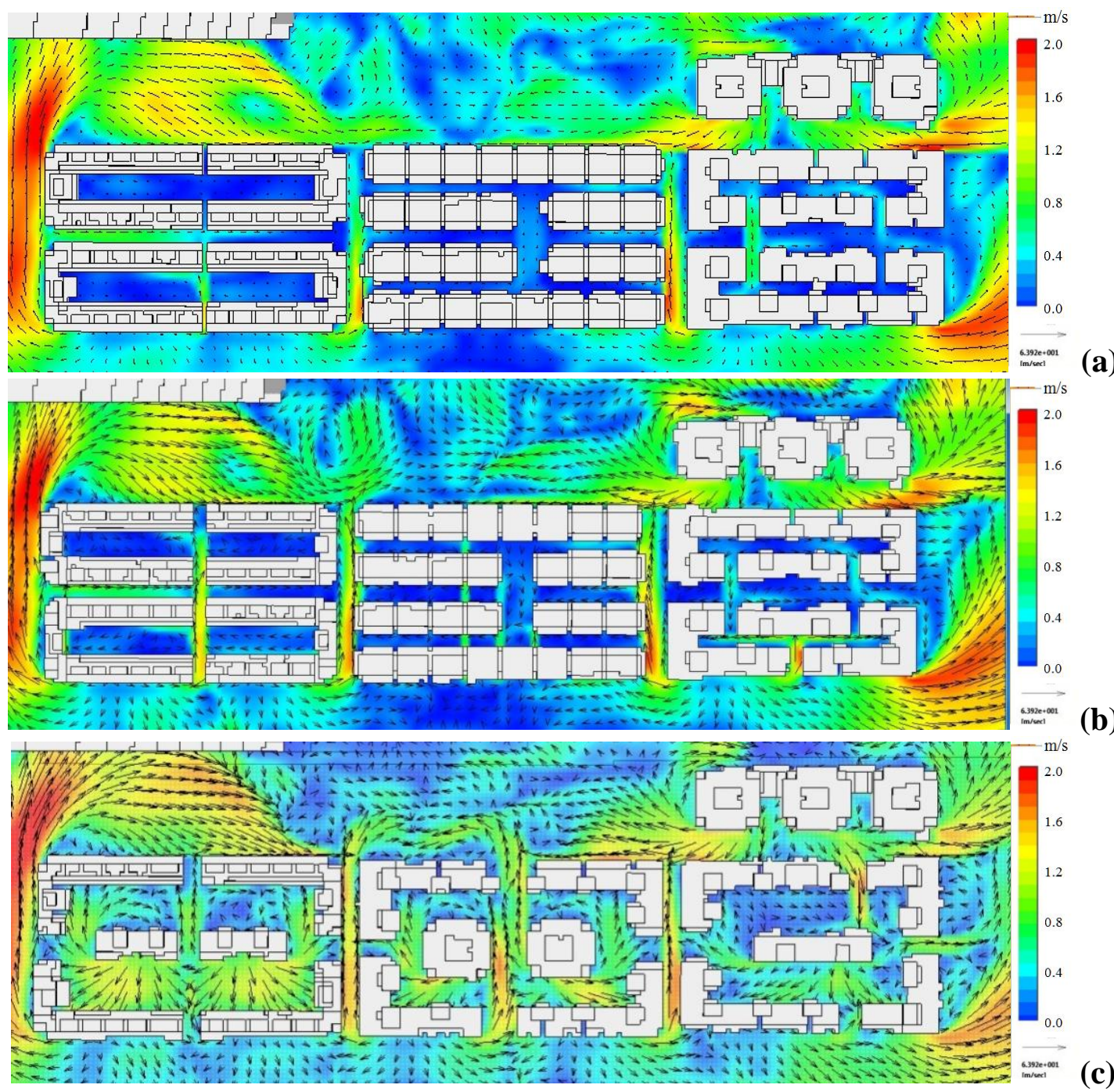

Figure 10. The CFD analysis result comparisons among three community building setting plans (partially enlarged drawing) (a) Current Plan. (b) Slightly-adjusted plan. (c) Climate-sensitive adjustment plan

For the minor adjustment plan (Plan 2), improvement of outdoor natural ventilation can be found in the areas close to the added ventilation openings or vents, such as those areas in housing Type B. However, for the community Type $\mathrm{C}$, because the distance between the buildings is too short, and the linear atrium is too narrow and long, the effect of the three newly added ventilation vents was found to be very limited, and the effect of wind guiding and natural ventilation resulting from the vents was not able to expand to the full scope of the atrium. Similar situation occurred in Community Type 
D, where the newly added ventilation vents in the four corners partially improved the natural ventilation of the nearby areas on the windward side. However, given that the community has a very closed narrow-shape atrium with only two small openings to the outside wind corridor, the effect of the newly added vents on the improvement of natural ventilation in the atrium were also found to be very limited.

In terms of the complete adjustment plan (climate-sensitive adjustment plan) (Plan 3 ), which redesigns the building blocks, housing types, building layout, and atrium openings based on the characteristics of the local wind corridor and the design principles of outdoor natural ventilation, the results of the CFD simulation met our expectations. As indicated in Fig. 10, for all the Housing Types B, C, and D communities, the CFD simulation results the natural ventilation of their atrium open space to be significantly improved, both for the entire atrium and for partial areas in the atrium. For the case of climate-sensitive adjustment plans, it was showed from the simulation results that the wind speed areas in the stagnant and poor wind speed classes were largely decreased. This indicates that in order to obtain the optimal effect of natural ventilation for a community open space, it requires a comprehensive consideration of the size of the building block, organization of building types, building masses, building layout, and the community atrium openings. Also, a careful study of the relationships between these design factors and the local wind corridor is indispensable.

Similar with the climate characteristics of high hot and humid in South-East Asia, this study area also has similar climate, and therefore the design issue of ventilation are needed to be considered. In Vietnam, natural ventilation was found a better choice for passive cooling due to its hot and humid climate (Nguyen and Reiter, 2014). In Jogjakarta, people seemed to prefer higher wind speed and showed a tendency of creating higher air movement to modify the hot and humid living environment (Feriadi and Wong, 2004).

Recent studies have shown that the geometry and aspect ratio of urban canyons play a crucial role in moderating the microclimate at the street level (Xie et al., 2006; Asfour, 2010; Du et al., 2017). Heights and layouts of building group were found to influence ventilation, and step up configuration can distribute the wind evenly and allow the wind to reach the leeward side of each building. It was shown very effective in improving the overall natural ventilation and thermal comfort at pedestrian level (Rajagopalan et al., 2014). Another research in Dhaka used H/W ratios as an index originally to represent uniform and diverse geometric character of different sites (Sharmin et al., 2017). In our study, we also found the building arrangement, building layout and atrium openings were important design issues for a good ventilation. However, only few openings facing the windward side was found limited for ventilation improvement. The different height of buildings in an urban block such as the combination of town houses and mid-rise buildings shown in this study were one of the better design criterion to create a better wind environment.

Besides hot and humid environmental analysis considered in this study, the other aspects that most of the above papers were not discussed is that we took land development, urban planning and residential type preferences into consideration. It was shown even under the premise of housing preferences and economic profits of land development, it is still possible to enhance ventilation environment of the external space of communities. All the above findings can be applied to other tropical cities. 


\section{Conclusion}

In order to provide a useful methodology and a suitable operational tool to integrate housing community design with climate-sensitive urban design, this study demonstrated a research approach which improves the natural ventilation of community atrium open spaces on an urban block scale with the help of a CFD simulation. Based on a review of related theories and literature as well as the analyses of current situation and suggested design alternatives, the study results show that this methodology has practical value in assisting community housing planning and design and is particularly useful for developing draft evaluations of strategic planning and design in determining building layouts and masses on site planning, where the simulation outcomes from this method could be used to modify design concepts and strategies. Moreover, by utilizing the proposed CFD simulation to analyze suggested scenario-based design alternatives to the natural ventilation of blocks and residential buildings as well as comparing the simulation results of the proposed improvements, this research shows that the method may enhance the scientific base of the traditional urban design approach because it can diagnose planning and design problems in the early stage of the design process and therefore guide the modification of design schemes on a timely and cost-efficient way.

Referring to practical community planning and design, the study analyzed and compared four typical types of housing community design and their atrium ventilation conditions. After a review of relevant literature, the CFD simulation parameters in our modeling approach were verified through on-site field survey of the microclimate situation. Subsequently, the atrium ventilation performance of four different housing communities in the selected four adjacent blocks was examined and compared through CFD simulations. This provides an operational method to integrate the consideration of climate-sensitive design approach into community design process.

Under the simulation condition with a prevailing wind from the south (long axis of the buildings facing prevailing wind), the research results indicated that the typical long-shape urban blocks with high density in southern Taiwan have poor natural ventilation in their atrium open spaces. The research also shows that if the openings of building masses and atrium could be arranged according to the prevailing wind direction, the community atrium ventilation could be improved greatly. It was also found from a comparison of the results of various design schemes that the natural ventilation in community atrium open spaces can be significantly optimized by properly controlling design factors including: the size and shape of urban blocks, the distances between buildings, organization of building masses, and the coordination of the openings of buildings and atrium open space with the direction of wind corridors. Furthermore, the results show that if a consideration of wind environment can be conducted in the early stage of community planning and design process, together with a proper CFD wind simulation approach, improvement in community external ventilation environments can be obtained without significantly reducing the expectation of developers who often attempt to meet the requirements of taking full use of all allowed Floor Area Ratio (FAR) and build more housing units to generate economic benefits in land development. In fact, this study reminds us that a good ventilation environment in community atrium open spaces will lead to a comfortable residential environment. If this concept can be accepted by developers and home buyers as well as be capitalized into property values, and subsequently lead to some adjustments in housing design preferences which take the concept of wind-sensitive design into consideration, more 
and more residential communities will be built with good ventilation environments, and therefore the goal of climate-sensitive urban design will be realized sooner than later.

Finally, it is worth mentioning that this paper provides a methodology and operational approach to integrate the concept of wind-sensitive design with community outdoor space design within the requirement local housing market practice and the expectation of land developers. But there are still many issues and limitations needed to be addressed in local housing market environment as well as in zoning, urban design, and building code regulations. It is suggested that more detailed and issued-based simulations of the relationship between wind environment and various design strategies and alternatives which meet local context and content should be conducted before setting up real design guidelines in conducting urban design control.

Acknowledgements. Part of the funding of this paper is from the Recruitment Program of Global Experts of Harbin Institute of Technology (HIT), China, when the first author was a distinguished professor at the Department of Urban Planning in HIT. The authors wish to thank the School of Architecture and the Department of Urban Planning of HIT for their support.

\section{REFERENCES}

[1] Allegrini, J., Dorer, V., Carmeliet, J. (2015): Influence of morphologies on the microclimate in urban neighbourhoods. - Journal of Wind Engineering and Industrial Aerodynamics 144: 108-117.

[2] Asfour, O. S. (2010): Prediction of wind environment in different grouping patterns of housing blocks. - Energy and Buildings 42(11): 2061-2069.

[3] Blocken, B., Janssen, W. D., van Hooff, T. (2012): CFD simulation for pedestrian wind comfort and wind safety in urban areas: General decision framework and case study for the Eindhoven University campus. - Environmental Modeling \& Software 30: 15-34.

[4] Chao, Y., Ng, E. (2014): Practical application of CFD on environmentally sensitive architectural design at high density cities: A case study in Hong Kong. - Urban Climate 8: 57-77.

[5] Du, Y.-X., Mak, C.-M., Liu, J.-L., Xia, Q., Niu, J.-L., Kwok, K.-C.-S. (2017): Effects of lift-up design on pedestrian level wind comfort in different building configurations under three wind directions. - Building and Environment 117: 84-99.

[6] Feriadi, H., Wong, N. (2004): Thermal comfort for naturally ventilated houses in Indonesia. - Energy and Buildings 36: 614-626.

[7] Givoni, B. (1998): Climate Considerations in Building and Urban Design. - New York, Wiley.

[8] Gromke, C., Blocken, B., Janssen, W., Merema, B., van Hooff, T., Timmermans, H. (2015): CFD analysis of transpirational cooling by vegetation: case study for specific meteorological conditions during a heat wave in Arnhem, Netherlands. - Building and Environment 83: 11-26.

[9] Hang, J., Luo, Z. W., Mats, S., Gong, J. (2013): Natural ventilation assessment in typical open and semi-open urban environments under various wind directions. - Building and Environment 70: 318-333.

[10] Hsieh, C.-M., Huang, H.-C. (2016): Mitigating urban heat islands: A method to identify potential wind corridor for cooling and ventilation. - Computers, Environment and Urban Systems 57: 130-143.

[11] Hsieh, C.-M., Wu, K.-L. (2012): Climate-sensitive urban design measures for improving the wind environment for pedestrians in a transit-oriented development area. - Journal of Sustainable Development 5(4): 46-58. 
[12] Hsieh, C.-M., Jan, F.-C., Zhang, L. (2016): A simplified assessment of tree allocation on wind environment and shading affecting human comfort. - Urban Forestry \& Urban Greening 18: 126-137.

[13] Hu, T. T., Yoshie R. (2013): Indices to evaluate ventilation efficiency in newly-built urban area at pedestrian level. - Journal of Wind Engineering and Industrial Aerodynamics 112: 39-51.

[14] Ishida, Y., Kato, S., Huang, H., Ooka, R.. (2005): Study on wind environment in urban blocks by CFD analysis wind velocity over street. - Research Report. Institute of Industrial Science, University of Tokyo, Japan.

[15] Jan, F.-C., Hsieh, C.-M., Ishikawa, M., Sun, Y.-H. (2013): The influence of tree allocation and tree transpiration on the urban microclimate: an analysis of a subtropical urban park. - Environment and Urbanization ASIA 4(1): 135-150.

[16] Lin, H. T., Sun, C. Y., Lee, K. P., Kuo, H. C. (2005): A study of urban population and the urbanheat island intensity in Tainan. - Journal of City and Planning 32(1): 83-97 (in Chinese).

[17] Lu, Y. R. (2008). Applying LST of remote sensing to explore the relationship between urban heat island effects and spatial development of social-economic. - Master Thesis of National Cheng Kung University (in Chinese).

[18] Mirzaei, P. A., Carmeliet, J. (2013): Dynamical computational fluid dynamics modeling of the stochastic wind for application of urban studies. - Building and Environment 70: $161-170$

[19] Mirzaei, P. A., Haghighat, F. (2010): Approaches to study urban heat island - Abilities and limitations. - Building and Environment 45(10): 2192-2201.

[20] Mochida, A., Lun, I. Y. F. (2008): Prediction of wind environment and thermal comfort at pedestrian level in urban area. - Journal of Wind Engineering and Industrial Aerodynamics 96(10-11): 1498-1527.

[21] Mora-Pérez, M., Guillén-Guillamón, I., López-Jiménez, P. A. (2015): Computational analysis of wind interactions for comparing different buildings sites in terms of natural ventilation. - Advances in Engineering Software 88: 73-82.

[22] Ng, E. (2009): Policies and technical guidelines for urban planning of high-density cities - air ventilation assessment (AVA) of Hong Kong. - Building and Environment 44(7): 1478-1488.

[23] Nguyen, A., Reiter, S. (2014): A climate analysis tool for passive heating and cooling strategies in hot humid climate based on Typical Meteorological Year data sets. - Energy and Buildings 68: 756-763.

[24] Peng, F., Wong, M.-S., Wan, Y.-L., Nichol, J. E. (2017): Modeling of urban wind ventilation using high resolution airborne LiDAR data. - Computers, Environment and Urban Systems 64: 81-90.

[25] Rajagopalan, P., Lim, K., Jamei, E. (2014): Urban heat island and wind flow characteristics of a tropical city. - Solar Energy 107: 159-170.

[26] Sharmin, T., Steemers, K., Matzarakis, A. (2017): Microclimatic modelling in assessing the impact of urban geometry on urban thermal environment. - Sustainable Cities and Society 34: 293-308.

[27] Shi, X., Zhu, Y.-Y., Duan, J., Shao, R.-Q., Wang, J.-G. (2015): Assessment of pedestrian wind environment in urban planning design. - Landscape and Urban Planning 140: 1728.

[28] Suder, A., Szymanowski, M. (2014): Determination of ventilation channels in urban area: A case study of Wrocław (Poland). - Pure and Applied Geophysics 171(6): 965-975.

[29] Takahashi, K., Yoshida, H., Tanaka, Y., Aotake, N., Wang, F. -L. (2004): Measurement of thermal environment in Kyoto city and its prediction by CFD simulation. - Energy and Buildings 36(8): 771-779. 
[30] Walton, D., Dravitzi, V., Donn, M. (2007): The relative influence of wind, sunlight and temperature on user comfort in urban outdoor spaces. - Building and Environment 42(9): 3166-3175.

[31] Wang, X.-X., Li, Y.-G. (2016): Predicting urban heat island circulation using CFD. Building and Environment 99: 82-97.

[32] Wu, K.-L., Hung, I.-A., Lin, H.-T. (2013): Application of CFD simulations in studying outdoor wind environment in different community building layouts and open space designs. - Advances in Mechanics and Control Engineering 2(3): 2317-2324.

[33] Xie, X., Huang, Z., Wang, J. (2006): The impact of urban street layout on local atmospheric environment. - Building and Environment, 41(10): 1352-1363.

[34] Yang, Y.-A., Juan, Y.-A., Wen, C.-Y., Chang, C.-J. (2017): Numerical simulation of cooling effect of vegetation enhancement in a subtropical urban park. - Applied Energy 192: 178-200.

[35] Yim, S. H. L., Fung, J. C. H., Ng, E. Y. Y. (2014): An assessment indicator for air ventilation and pollutant dispersion potential in an urban canopy with complex natural terrain and significant wind variations. - Atmospheric Environment 94: 297-306.

[36] Yuan, C., Ng, E., (2012): Building porosity for better urban ventilation in high-density cities - A computational parametric study. - Building and Environment 50: 176-189. 